\title{
Nephropathic infantile cystinosis
}

INSERM

\section{Source}

INSERM. (1999). Orphanet: an online rare disease and orphan drug data base.

Nephropathic infantile cystinosis. ORPHA:411629

Nephropathic infantile cystinosis is the most common and severe form of cystinosis (see this term), a metabolic disease characterized by an accumulation of cystine inside the lysosomes that causes damage in different organs and tissues, particularly in the kidneys and eyes. 